\title{
Performances, preservation and policy implications: digital curation and preservation awareness and strategy in the performing arts
}

\author{
Laura Molloy \\ Digital Curation Centre \\ Humanities Advanced Technology and Information Institute (HATII) \\ University of Glasgow, G12 8QJ, Scotland \\ Laura.Molloy@glasgow.ac.uk
}

\begin{abstract}
Digital assets in contemporary performing arts practice are vulnerable to damage and disappearance, eroding prospects of a coherent record of contemporary practice and its place in our wider digital cultural heritage. This paper summarises a study that seeks to understand and assess this threat so that appropriate solutions - if necessary - can be scoped and provided in a way accessible both to the practitioner and the research and academic/training communities. A series of case studies was developed examining the digital curation and preservation awareness and practice of a sample of UK-based performing arts professionals. This approach provides a 'practitioner's-eye view' of the types of digital objects used by this community; current curation strategies and activities; and the factors that influence digital curation and preservation decisions.
\end{abstract}

This study establishes that digital objects are highly prized by the professional performance community. Accordingly, expectations of the survival of these digital objects are high, but investigation found that levels of sustainable digital curation and preservation practice are low. These findings support the argument that competent digital curation and preservation practice is relevant to the sustainability of a career in the performing arts, as well as of benefit to the arts researcher or student and cultural heritage more widely. These findings reveal the need for an effective response in order to mitigate the loss of digital cultural heritage in this professional sector.

Preservation of the digital cultural objects that are created, shared and sought by performing arts practitioners is subject to the economic realities of professional practice and also constrained by current levels of practitioner digital curation awareness and competence. These skills are not yet routinely taught in practitioner training institutions. There is an urgent need i) to promulgate policies based on a sound knowledge of digital curation and preservation practices in the professional performing arts community; and ii) for a coherent strategy to develop practitioner knowledge and skills, and to deliver such training in language accessible to the community of practice.

This paper describes the problem, my research approach, and

Please leave this box empty for a copyright notice my findings and recommendations, and is intended to be of interest to all those engaged in policy and skills development in communities of practice beyond the academy, particularly in the creative arts and cultural heritage domains.

\section{Keywords}

Digital preservation, digital curation, performing arts, cultural heritage, personal archiving strategies, community approaches to preservation, sustainability.

\section{INTRODUCTION}

Practitioners of the performing arts working beyond the higher education (HE) institutional context regularly produce work on limited project funding, to tight deadlines and with little time or money to consider if and how they might best undertake the curation of their digital assets. Without specialist expertise, digital assets created and used by performance practitioners are vulnerable to damage and disappearance, eroding prospects of a coherent record of contemporary performance practice and its place in our wider digital cultural heritage.

For the purposes of this paper, the performing arts are 'the disciplines of music, theatre, dance, film, television, radio and other performance forms such as live art' [1] - a definition based upon a scrutiny of the areas of practice taught in performing arts tertiary education institutions across the UK.

Much of the existing scholarly literature which addresses digital curation and preservation within the performing arts focuses on practitioners working inside the academy $[1,2,3,4]$ or on the problems faced by gallerists or archivists who are responsible to an institution for the collection and care of digital objects that have been created by performance practitioners $[5,6,7]$. A welcome contribution has been made by the InterPARES 2 initiative [8] in its valuable attempts to initiate the development of tools and guidance specifically for the creators of digital objects as part of professional practice, although some resources are no longer available online at the time of writing.

The limited amount of work that examines digital curation awareness and skills in institutionally-based performance practice also highlights the need for fuller and further examination of the digital curation and preservation knowledge and processes of performing arts practitioners working outside institutional structures. This gap can only be filled by engagement with professional performance arts practitioners who are not primarily supported by academic funding streams or institutional infrastructures; as such, a sample of these practitioners was interviewed for the current study. Some respondents work as performers and some in creative roles such as playwright, director or choreographer, but all practitioners addressed in this study have key responsibility for creative 
decision-making. The term 'practitioner' is preferred here to 'artist' or 'performer' as not all professionals responsible for key creative decisions in the performing arts appear on the stage. The current study is primarily concerned with the presence or absence of digital curation skills and competences among these practitioners.

\section{DIGITAL OBJECTS, CURATION AND PRESERVATION IN THE PERFORMING ARTS}

A digital object is an object composed of a set of bit sequences [9]. The term 'digital object' encompasses a wide variety of file types (text, video, audio, etc.) and formats (MP3, PDF, JPG, etc.) which are created and used by performance arts practitioners, and the variety of purposes for which practitioners create and use their digital objects (e.g. as an element of a production, note-taking at rehearsal, documentation of a staged presentation, etc.) Digital objects are vulnerable to damage and loss of access, and require proactive intervention to remain accessible [10] and to retain their authenticity. An 'authentic' digital object, in digital curation terms, is defined by the Digital Preservation Coalition as one which is "the same as it was when it was first created" [11].

Digital curation is the active management of digital objects over time and encompasses digital preservation, data and electronic records management, and digital asset management [12]. Since 2010, the Digital Curation Centre has provided a Curation Lifecycle Model to illustrate the actions and processes required to curate and preserve digital objects [13]. This model situates the digital object at its centre, surrounded by the activities continuously necessary throughout the entire lifecycle of the digital object for sustainable curation to take place. These activities are represented by three concentric layers surrounding the digital object. The model shows that the digital object must be associated with description information, in the form of appropriate metadata, throughout its lifecycle. Representation information is also continuously necessary so that the object and its metadata can be understood and rendered correctly in the user's technical environment. Planning for the management and administration of digital curation actions is also continuously required throughout the object's lifetime. Continuous engagement within the wider digital curation community is also advocated by this model. Surrounding these continuous activities are the sequential actions and processes involved in curating and preserving the object. Conceptualization of the object results in its creation or reception whereupon it becomes manifested as a digital object and can enter the digital curation lifecycle. It is then either selected for preservation or disposed of. Once received, or ingested, into the preservation environment, it can then be sustainably stored in such a way that it is potentially available for re-use and transformation into a new asset, which in turns becomes eligible to enter the curation lifecycle. In this way, the Curation Lifecycle Model explicitly enshrines creative engagement with digital objects as part of the overall cycle of activity. This renders the Curation Lifecycle Model particularly useful to those working with digital objects in the creative arts sectors.

The term 'curation' has a long-standing association with the care of various types of objects or collections of objects, including our bodies, paperwork, collections of scientific specimens or artworks, and, more recently, the type of collection ubiquitous in both professional and in private life: digital objects [14]. 'Digital curation' may be a challenging term to employ with clarity in the performing arts - particularly - due to the established resonance of the term 'curation' in the cultural heritage sector to describe responsibilities such as selecting and interpreting cultural artefacts for public display in the gallery or museum. In addition, 'digital curation' is frequently used synonymously or interchangeably with 'digital preservation'. To disambiguate, digital preservation 'refers to all of the actions required to maintain access to digital materials beyond the limits of media failure or technological change' [11]. The proximity of meaning between the two terms, then, is clear as a significant amount of the territory claimed by each overlaps. However, as the Curation Lifecycle Model makes clear, digital curation explicitly includes the conceptualization of a digital object and extends through the entire lifecycle of the digital object to its capacity to be transformed into new knowledge, thought or work. Digital curation incorporates and is confluent with the aims and activities of digital preservation, which is expressed as a phase within the Curation Lifecycle Model, and so the term 'digital curation' is used here as a shorthand for the complete and iterative lifecycle of actions or transformation points - including the full range of preservation activity - of digital objects. To accomplish the greatest potential benefit from the ideas encapsulated by the Curation Lifecycle Model, each of the sequential actions specified by the model requires particular skills and competences appropriate to the type of object and context of the curation activity.

\subsection{The Need for Skills}

The wide availability of affordable digital recording devices has allowed contemporary professional practitioners of the performing arts to become active in the creation of digital objects in the course of researching, rehearsing and creating their work, and also in documenting rehearsals and staged presentations. This implies that practitioners are, to varied extents, dependent upon the continued existence of these digital objects in order to complete the tasks of researching, creating, experiencing, communicating and selling performance work. Further, to participate in the emerging digital cultural heritage ecosystem, performance arts practitioners will increasingly find that the ability to create, manage and preserve their digital assets is an important skillset. It is apparent, then, that digital curation and preservation skills are already important - perhaps even necessary - for performing arts practitioners.

Practitioners who graduate from tertiary education will as a minimum have been influenced by the skills they were taught as students. However, there is little evidence in the existing literature to suggest that digital curation advocacy or skills are currently routinely embedded in tertiary education programmes in the performing arts.

\section{2 'Documentation' and 'Preservation'}

Discussion of preservation practices in the performing arts is often very quickly co-opted into a discussion specifically of the documentation of live performance work. However, it is critical for the purposes of the present discussion to clarify that, in current performing arts practice, the creation of documentation is only one of the activities that results in the production of digital objects. In other words, 'digital objects in the performing arts' and 'objects created in order to serve as documentation of performance' are not equivalent and interchangeable groupings, although the two categories clearly overlap.

Performance studies literature tends to address the notion of documentation of performance in a more philosophical sense than the approach taken by digital curation scholarship. Performing arts research is more prone to consider whether or how the live performance event can persist into another time or in another place. When documentation is created, this leads into considerations of the role or potential or appropriateness of accessing the live event via documentation as discussed, with 
various conclusions, by Auslander [15], Reason [16], Jones [17] and Phelan [18], inter alia.

In comparison, digital curation is more concerned with how another user (or the creator themselves, at a future point) can find, understand and re-use documentation, however it is constituted in digital form. The creation of documentation, from this perspective, is merely the first step in a series of deliberate activities that are necessary in order to allow the digital object to persist.

Much performing arts scholarly literature conflates the two concepts of documentation and of archive-related activities such as preservation: for example, "to archive is synonym with to document, to archive is to do documentation" [16]. In contrast, from the digital curation perspective documentation and preservation are understood as distinct, if related, activities.

\section{PRACTITIONER PERSPECTIVES}

\subsection{Case Study Interviews: Aims and}

\section{Approach}

In order to better understand professional performance practice outside the institutional context, this study aimed to establish the knowledge and experience of performing arts practitioners about digital curation including which preservation decisions they make when they are independently responsible for the management of their digital objects and are not being guided by an institutional policy or set of requirements.

To ensure that the enquiry remained focused on the heretofore under-studied group of practitioners from beyond the HE sector, it was necessary to identify individuals who were making their creative income mainly from non-HE funding streams. The creative industries rarely provide clear professional paths or simple, linear career progression and it is recognised that most performing arts professionals rely on a number of income streams. Subjects of the current survey were not exempt from this. An intimate relationship exists between those working in the performing arts within and outside the HE system. To a certain extent, then, an attempt to sort performing arts professionals into two set groups - HE / non-HE - with a impermeable barrier between would be artificial, but it can be reasoned that at least the bulk of professional performing arts activity undertaken by an individual can, at any given point in their career, be viewed as 'usually funded by $\mathrm{HE}$ funding sources' or 'usually funded in other ways'. Whilst perhaps a prosaic way of categorisation, it appears to be as effective as any other and - crucially - understood by the respondents interviewed. Two internationally-renowned performance makers were initially approached and agreed to participate. Each subsequently suggested further subjects likely to engage with the enquiry, so the 'snowball' sampling technique [19] allowed the dataset to expand to twelve participants, recruited through professional networks. This approach provided respondents from a variety of nationalities, ages and performing arts disciplines. The sample is not sufficient to be representative of the estimated 400,000 or so professionals working in the performing arts in the UK [20] but some noticeable trends emerged from the sample that suggest further work in this area would be useful for verification of these results.

Semi-structured interviewing was employed to ensure that the full framework of questions was addressed, but also to provide ample opportunity to follow any questioning routes suggested by the respondent and to capture any further questions, concerns or relevant information from each interviewee.

\subsection{Interview Questions}

Questions in the interview explore current digital object creation and management choices, and the sources practitioners used when attempting to access digital objects created by others. This provided a 'practitioner's-eye view' of performance collections, which is to say the resources they used as collections for research, irrespective of the formal designation or intended purpose of such resources.

Interview questions were laid out in the following order:

Section 1: 'Your Work':

- $\quad$ The type of performance work being made and how it is funded;

- Professional interaction with $\mathrm{HE}$;

Section 2: 'Preservation of Your Work':

- Understanding of the notion of 'preserving' work;

- Understanding of the notion of an archive;

- Whether it is important to preserve work, both in general and to the subject personally;

- What - if anything - respondents do in terms of managing or preserving their digital objects;

- $\quad$ The anticipated lifespan of preserved digital objects;

- The purposes for which subjects use / intend to use the digital objects they create;

- Willingness to share preserved digital objects;

- $\quad$ Experience of digitization;

- Interest in accessing professional archive care for digital objects;

Section 3: 'Your Use of Archives':

- Where respondents look to find digital objects in the course of their work;

- $\quad$ The importance of digital objects created by others to creative workflows;

- How often digital objects are searched for;

- $\quad$ The purposes for which subjects use / intend to use digital objects created by others;

- $\quad$ Types of objects that are considered useful;

- $\quad$ Resources that may be useful to respondent's practice but are not available / accessible.

Respondents were also provided with an opportunity to raise any other relevant points or concerns.

\section{FINDINGS}

\subsection{Interview Section 1: The Type of Performance Work Being Made and How It Is Funded}

Three of twelve respondents worked in a single field, area or medium: the others worked in two or more areas. The most frequent number of areas of specialization reported was two (five respondents). The most frequently reported area of activity is as musician (four respondents). Thirteen areas in total were suggested by respondents: playwright, director, stage performer, stage producer, dancer/choreographer, performance artist, live artist, singer, film performer, film-maker, musician, script/screenwriter and songwriter. A clear majority of practitioners in this sample, then, usually worked across more than one area of the performing arts. Findings do not suggest any clear relationship between particular areas of professional practice and levels of knowledge or skill in digital curation. This in turn suggests that, in the sample population at least, there are common challenges to sustainable digital curation across all areas of the performing arts.

Funding strategies in the respondent group largely rely upon two main sources of money: self-funding and public funding. Eight respondents of twelve reported 'self-funding' which was defined with participants to mean private income, salary and other funds that are not directly accrued as a result of creative 
practice. Seven respondents benefitted from Creative Scotland (formerly the Scottish Arts Council and Scottish Screen) funding. Two respondents listed various other sources of public funds. If this trend is replicated across the sector as a whole, it suggests that public funders are potentially in a position of great influence on the priorities and activities of live and performing arts practitioners, given that such a large proportion are in receipt of their support.

\subsection{Interview Section 2: Preservation of Your Work}

This section of the interview seeks to establish what practitioners understand by the term 'preservation' in the context of their creative work. Of the twelve respondents, one directly asked for clarification of the term 'preservation' and a further eight indicated uncertainty in answering. The most frequent response (eight respondents) was to equate 'preservation' with the creation of digital documentation of live work, without any particular reference to how the resulting digital objects are managed over time. This conflation of object creation and object curation is a key finding of the current study and does much to explain the apparently low levels of digital curation awareness and activity in the sample group. In most cases, the job is considered complete once the digital object is created and burned to CD or DVD. However, good practice in the creation of digital objects is understood as part of overall competent digital curation practice, as articulated by the 'Conceptualise' and 'Create or Receive' phases of the DCC's Curation Lifecycle Model.

Respondents were asked whether it is important for performing arts practitioners in general to preserve their work. All respondents answered yes, seven without further qualification of that response. Three respondents reported ambivalence, with their answer as 'yes' in some scenarios and 'no' in others (for example, that they believed preservation to be important in general but not specifically for their own work). Five respondents discussed the ephemeral nature of performance as valuable but only one of those five expressed the view that the value of ephemerality precluded the value of documenting the live work. Preserved traces of performance, i.e. those created both by the respondent and by other practitioners, were described as valuable for various purposes in the course of answers to this question, including value as a resource for research (five respondents), economic or cultural value (four) and as a source of historical knowledge within the discipline (three).

The interviewees were also asked directly whether they preserved their own work and if so, how they went about it. Here, the term 'preserved outputs' was used in the question to attempt to disambiguate between the creation of documentation and the preservation of these objects. Almost all respondents (eleven) claim that they 'preserve' their own work. Consideration of the most frequent responses here indicates that this was largely understood to equate to putting analogue and digital objects into a physical box (eight respondents), and the creation of documentation (explicitly described by seven respondents). These responses largely equated the creation of digital objects with their curation or preservation. The only digital preservation task mentioned by seven of the respondents was backing up; three of these responses came from those reporting explicitly that the digital objects they produce are documentation of live performance. Four respondents reported that their work is born-digital; two of them back up their work. There is no particular indication in the responses that those creating digital objects in the course of born-digital work are any more aware of digital curation than those creating digital objects only in the course of documenting their creative work.
Most respondents (ten) were able to describe a particular use for the digital objects they created. Eight respondents value their digital objects for use in promotion or marketing of their creative work. Other uses are noticeably lower, including for commercial release (four respondents), in order to be able to restage performances or to enable artistic development (both reported by three respondents). Other uses of digital objects created by the respondent included: for personal reflection; as raw material for new work; as creative inspiration for new work; as elements of live production; for use in teaching; for communication with remote collaborators; and as evidence for funding applications (each reported by either one or two respondents). There is an appetite for making digital objects created by the respondent available for research by other practitioners: ten respondents are in favour although five respondents are unsure whether their material would be of interest or value to other people.

In the course of creative practice, digital video is created and stored by nine respondents; digital audio by seven respondents; digital images by six, and texts by four. One respondent reported not creating digital objects as part of his own creative practice, but did create such objects for others and received such objects from other people. Eight respondents expect the digital objects they created to be available to them in perpetuity or at least as long as they still wanted access to them.

Respondents were also asked for their separate definitions of an archive and a digital archive. Seven respondents specify accessibility as an expected feature of archives. Six respondents hold the issue of accessibility of content as part of their definition of a specifically digital archive, and five that a digital archive implies one that is available for access online.

Five respondents are concerned about managing user access, intellectual property rights (IPR) or copyright, commercial exploitation, the presentation of objects or a general sense of feeling that the work is under their control, but most still support a dedicated external resource. Seven respondents considered professional skills for the curation and preservation of digital objects skills as a benefit of deposit in a third-party archive. Six respondents see the ability of such an external resource to provide wider access to artists, students, researchers and the general public as a benefit.

\subsection{Interview Section 3: Your Use of Archives}

Respondents were asked to list any collections, archives or resources related to the performing arts, whether digital or not. Ten respondents supplied examples, either of performing artsspecific resources or more general resources that contained performing arts-specific material. Forty-six resources were named overall; thirty-one specifically provided or held performing arts resources and the remainders were more general resources containing performing arts-related material.

Given a four-point scale ('Extremely', 'Somewhat', 'Not Really' and 'Don't Use Them'), seven respondents rated the use of these digital resources as 'somewhat' important to the research and preparation of their own work. A further two respondents rated them as 'extremely' important. Frequency of use followed a similar pattern: seven respondents reported using digital resources once a week or more, all of whom had described use of these resources as either 'somewhat' or 'extremely' important.

The most common reasons using digital resources in research and practice were for factual research (eight respondents); abstract inspiration (seven respondents) and practical ideas (six respondents). Respondents were asked what sort of materials would be useful in digital resources for the performing arts. Results are tabulated in Table 1. Most types of resource were 
equally popular - only raw data (g.) was chosen by less than half of respondents.

Table 1: Perceived usefulness of different types of digital resource

\begin{tabular}{|l|l|}
\hline Type of resource & $\begin{array}{l}\text { Frequency } \\
\text { of rating: } \\
\text { useful } \\
\text { (n=12) }\end{array}$ \\
\hline Collections of links to relevant websites & 11 \\
\hline Bibliographies relevant to particular subjects & 11 \\
\hline Searchable raw materials: video & 11 \\
\hline $\begin{array}{l}\text { Analytical or interpretative material (e.g. } \\
\text { articles on aspects of performance) }\end{array}$ & 11 \\
\hline $\begin{array}{l}\text { Materials documenting the final performance or } \\
\text { product (e.g. a digital film, or a video of a } \\
\text { dance) }\end{array}$ & 11 \\
\hline Searchable raw materials: audio & 10 \\
\hline $\begin{array}{l}\text { Integrated resources (e.g. text with images, } \\
\text { musical scores with recordings) }\end{array}$ & 10 \\
\hline Searchable raw materials: images & 10 \\
\hline $\begin{array}{l}\text { Searchable raw materials: text (e.g. play } \\
\text { scripts) }\end{array}$ & 9 \\
\hline $\begin{array}{l}\text { Materials documenting the process of creating } \\
\text { the performance or product (e.g. director's } \\
\text { notes, rehearsal techniques, costume or lighting } \\
\text { design, recording techniques) }\end{array}$ & 8 \\
\hline Raw statistical data (e.g. audience figures) & 5 \\
\hline
\end{tabular}

Digital resources discussed were largely online, but can also be circulated using other channels. All respondents used offline digital resources in research for and preparation of their creative work. Eight respondents used DVDs and seven used CDs. These were most commonly purchased (six respondents) or borrowed from peers and professional contacts (four respondents).

\section{DISCUSSION OF FINDINGS}

\subsection{Digital Object Creation and Use}

Overall, digital object creation and use is widespread in this sample. A majority of respondents appear to equate the creation of digital objects in the course of their creative process with preservation of their work for the future. Often, performers hope, dream or expect that they have somehow captured - to some, preserved - live and performing arts work when in fact what they have achieved is the creation of partial documentation of one or some aspects of it.

Responses demonstrate a pragmatic approach to the creation and use of digital objects. It is often the impression given in academic discourse in the performing arts that practitioners privilege - or at least ought to privilege - the ephemeral live moment over the documented trace, a position supported by Phelan [18], Barba [21] and others. However, in the current study this is not a prevalent attitude. All respondents believe that performance arts practitioners en masse should preserve their work. Less than half of the respondents raised the issue of the value of the ephemeral nature of performance as a critical issue at all, and only one respondent expressed the view that the value of ephemerality precluded the value of documenting practice; and even that only in certain situations. All respondents create and use digital objects as part of their practice. Professional practice, then, appears to be more in line with the arguments for the validity of digital representations of work as presented by Auslander [15], Jones [17] and others.

Nearly all respondents 'preserve' their own creative work, albeit by understanding this to mean creating documentation and storing physical and digital items in unmanaged storage. Only one respondent showed awareness of the limited lifespan of carrier media, implying that when objects are stored on carrier media such as DVDs, they are not regularly checked or refreshed. Such choices effectively amount to unmanaged, "benign neglect" [22]. As has been noted in digital curation scholarship, however, "benign" means free from intentional damage; unintentional damage is still likely to occur: "[d]igital objects do not, in contrast to many of their analogue counterparts, respond well to benign neglect” [23].

\subsection{Access}

Responses in both Section 2 and 3 indicate a marked appetite for and high expectations of perpetual access to authentic digital objects. Two thirds of respondents assume that their digital objects will be findable, available (and presumably intact) perpetually, or at least as long as they are of interest. Almost half of respondents consider access to digital objects for the use of the original creator, other practitioners, researchers and/or the public to be an important function of any preservation activity. Over half of respondents expect a performing arts-related archives or collections to be widely accessible, whether digital or not. Nearly all respondents are in favour of their digital outputs being accessible to other practitioners for research purposes and most are comfortable with a dedicated, external resource providing and managing this access. All respondents who reported a particular use for their digital objects described using them to bring about an economic benefit: particularly by use of these objects for promotion or marketing of creative work, or by sale as a commercial release.

\subsection{Awareness and Skills}

Respondents report low levels of active management of their digital objects, or awareness of the need for such digital curation and preservation practices. If the results of this study are representative of the non-university-based live and performance arts practitioner community more widely, then this is a population of practitioners who make ephemeral work and want to digitally retain traces of that work that will last in perpetuity, ensuring it is widely and reliably available. Furthermore, this population already believes it is effectively preserving these digital traces, and already relies on the sustained existence of these traces for economic benefit and to contribute to the creative process. Once practitioners have been made aware of the relevance of good digital curation practice to their digital assets, the motivation and the enthusiasm for good digital curation practice are both present; awareness, training and support for improved digital curation practice, specifically the active management of digital objects over time, are currently absent.

This study indicates that performance arts practitioners may urgently need to become aware of the risks to which their digital objects are currently subject. Additionally, training may be needed to give funded practitioners access to sufficient digital curation skills to allow the creation of high quality and sustainable digital objects. Practitioners in possession of such skills will be in a position to make and implement more information choices in their own digital curation practice as well as potentially contributing to a cultural shift within their areas of specialization.

Respondents also do not demonstrate particular knowledge or skills in information-seeking practices: for example, they do not discriminate between different types of online resource. Most 
practitioners rely on searching the open web to find digital resources or objects within these resources.

Given their responsibility for administration of public funds, appropriate flagship organizations such as the major arts funding agencies would be appropriate bodies to provide awareness-raising and training: these already operate within the digital ecosystem and are reliant upon sustained access to authentic digital objects. For example, applications for Creative Scotland funding are expected to arrive supported by digital documentation of previous creative work in the form of digital audio, video or images. The decision to fund or reject a bid for support is taken at least partly on the evidence provided by such digital documentation, indicating the importance in the funding relationship of high quality, well-described digital objects that can be reliably found and accessed. But there is nothing in Creative Scotland's bidding documentation to guide the practitioner on the creation of high quality digital objects, and storage and sharing solutions recommended are commercial cloud services. Such commercial services are highly problematic because they have no obligation to sustain service beyond short-term payment or even, in some cases, respect UK intellectual property rights legislation [24].

\section{CONCLUSION}

The overall picture, then, is one where digital objects are considered to be a central part of the processes of production and reception of live and performing arts, and of making a living as a performing arts practitioner. Responses to the interview questions here allow a gap to become visible between practitioners' ambitions for the longevity and authenticity of their valued digital objects and the likely result of their current digital preservation and curation-related decisions. This is arguably the primary finding of this study.

Further research in this area might usefully concentrate on the production of a larger, expanded study in order to provide results capable of representing the wider UK performance arts community; the current sample is too small to provide this.

There is, then, an apparent need for increased practitioner awareness of the benefits of better management of digital objects and for some attempt at training provision for the community that could be usefully supported by the development of guidance and standard-setting by creative funders.

\section{ACKNOWLEDGMENTS}

My sincere thanks to Dr Toni Sant (University of Hull), Dr Maria Economou and Ann Gow (University of Glasgow), Dr William Kilbride (Digital Preservation Coalition), Dr Simon Hodson (CODATA), Prof Seamus Ross (University of Toronto), the TaPRA Documenting Performance Working Group, and all my colleagues at the Digital Curation Centre particularly Kevin Ashley, Dr David Wilson and Joy Davidson, for their contributions of various kinds to this work.

\section{REFERENCES}

[1] Abbot, D. and Beer, E. 2006. Getting to Know Our Audience: AHDS Scoping Study. Glasgow: AHDS Performing Arts, 6.

[2] Gray, S. 2009. 'Documenting Performance Art for the Archive', Kultivate project Case Study, Bristol, University of Bristol, p. 2. Available at http://www.vads.ac.uk/kultur2group/casestudies/Bristol20 11.pdf.

[3] Gramstadt, M. 2013. 'Jisc final report: KAPTUR project', v1.1. Available at http://www.vads.ac.uk/kaptur/outputs/KAPTUR_final_rep ort.pdf.
[4] Guy, M., Donnelly, M. and Molloy, L. 2013. 'Pinning It Down: Towards a Practical Definition of Research Data for Creative Arts Institutions', International Journal of Digital Curation, 8, 2, 99-110. DOI=http://dx.doi.org/10.2218/ijdc.v8i2.275.

[5] Rinehart, R. 2000. 'The Straw that Broke the Museum's Back? Collecting and Preserving Digital Media Art Works for the Next Century', blogpost dated 14 June 2000. Available at http://switch.sjsu.edu/web/v6n1/article_a.htm.

[6] Bouttell, S. 2005. 'The Challenges Facing Archivists in the Documentation and Preservation of Time-Based and Variable Media'. Thesis submitted 16/9/2005. International Centre for Cultural and Heritage Studies, University of Newcastle. Held by BALTIC archive, item ID: 34368

[7] Matters In Media Art project, described at http://www.tate.org.uk/about/projects/matters-media-art.

[8] Hackett, Y., Underwood, W., Eppard, P. (2008). 'Case and General Studies in the Artistic, Scientific and Governmental Sectors: Focus Task Force Report: focus 1 the Arts', in Duranti, L. and Preston, R. (eds.) (2008). International Research on Permanent Authentic Records in Electronic Systems (InterPARES) 2: Experiential, Interactive and Dynamic Records. Padova, Italy: Associazione Nazionale Archivistica Italiana, pp. 17-28. Electronic version available at http://www.interpares.org/display_file.cfm?doc=ip2_book _complete.pdf.

[9] Consultative Committee for Space Data Systems (CCSDS). 2012. Reference Model for an Open Archival Information System (OAIS): Recommended Practice. Available at http://public.ccsds.org/publications/archive/650x0m2.pdf.

[10] Digital Preservation Europe (DPE). 2006. "Why should we care about digital preservation?” Available at http://www.digitalpreservationeurope.eu/what-is-digitalpreservation/.

[11] Digital Preservation Coalition (DPC). 2008. Digital Preservation Handbook. Available at http://www.dpconline.org/advice/preservationhandbook/in troduction/definitions-and-concepts.

[12] Yakel, E. 2007. "Digital curation.” OCLC Systems \& Services 23 (4): 335-340.

[13] Digital Curation Centre (DCC). 2014. Curation Lifecycle Model. Available at http://www.dcc.ac.uk/resources/curation-lifecycle-model.

[14] Lee, C. A., and Tibbo, H. 2011. Where's the archivist in digital curation? Exploring the possibilities through a matrix of knowledge and skills. Archivaria, 72 (Fall 2011), 123-168.

[15] Auslander, P. 2008. Liveness: Performance in a Mediatized Culture. 2nd ed. Oxon: Routledge.

[16] Reason, M. 2006. Documentation, Disappearance, and the Representation of Live Performance. Palgrave Macmillan, 31.

[17] Jones, A. 1997. “'Presence' in Absentia: Experiencing Performance as Documentation”. Art Journal 56 (4): 1118. College Art Association. http://www.jstor.org/stable/777715.

[18] Phelan, P. 1996. 'The Ontology of Performance: representation without reproduction.” Unmarked: the Politics of Performance. Oxford, Routledge. 
[19] Bryman, A. 2012. Social research methods. Oxford university press, 424.

[20] UK Government Department for Culture, Media and Sport. 2015. Creative Industries: Economic Estimates. January 2015: Statistical Release. https://www.gov.uk/government/uploads/system/uploads/a ttachment_data/file/394668/Creative_Industries_Economi c_Estimates_-_January_2015.pdf

[21] Barba, E. 1992. "Efermaele: "That Which Will Be Said Afterwards”.” The Drama Review 36 (2): 77-80.
[22] Tibbo, H. 2003. "On the Nature and Importance of Archiving in the Digital Age.” Advances in Computers 57: 2-69.

[23] Ross, S. 2007. "Digital Preservation, Archival Science and Methodological Foundations for Digital Libraries.” Keynote Address at the 11th European Conference on Digital Libraries (ECDL), Budapest, 17 September 2007.

[24] Aitken, B., McCann, P., McHugh, A. and Miller, K. 2012. Curation and the Cloud: Final Report. London: Jisc. http://www.jisc.ac.uk/media/7/C/1/\{7C1A1FD7-44B44951-85A8-FC2C4CEB1564\}Curation-in-theCloud_master_final.pdf 